\title{
THE STRUCTURE AND CHARACTERISTICS OF TRIBOLOGICAL SYSTEMS WITH DIAMOND LIKE CARBON COATINGS UNDER IONIC LIQUID LUBRICATION CONDITIONS
}

\begin{abstract}
The results from the tests on tribological a-C:H diamond coatings deposited by PACVD (plasma assisted chemical vapour deposition) on 100Cr6 steel components are presented in this work. Mechanical properties - nanohardness and Young's modulus - were assessed by instrumented indentation. Tribological tests were conducted with T-01M tester in a ball-on-disc test under dry and boundary friction conditions. Selected ionic liquids - synthetic new generation lubricants - were used for lubrication. The results from the experiments indicate that diamond-like coatings improved tribological characteristics of the friction pairs tested, with the ionic liquids intensifying this effect.
\end{abstract}

Keywords: Diamond like carbon coatings, ionic liquids, SEM, nanoindentation, friction, tribological wear

\section{Introduction}

The lifetime of contact surfaces is for the most part determined by their resistance to wear [1]. Durability and reliability of tribological systems in service can be enhanced by selecting adequate materials [2] and by coating the working elements with anti-wear films adapted to particular working conditions. The performance of machine components depends not only on the load-carrying capacity in the entire cross-section of the material, but mainly on the structure and characteristics of the surface layers $[3,4]$. For a coating to meet the required criteria, a suitable combination of physical, chemical and mechanical properties must be ensured, including high hardness, resistance to shear stress and bending, fracture toughness, resistance to friction wear and corrosion, and good adhesion on the substrate [3,5-10]. Further investigations of the materials and lubricants are necessary to be able to address stringent requirements of the market. The studies of DLC diamond-like coatings and ionic liquids in tribological systems are one of the directions to choose in those investigations. Insufficient knowledge about the interaction of DLC coatings with the constituents of the lubricants in pairs in which at least one surface is coated with an anti-wear film is a barrier to the development of much broader applications [11].

Diamond-like coatings were first discovered by Aisenberg and Chabot [12]. While cooling a low-energy carbon ion beam in the argon environment, they produced hydrogen-free amorphous carbon films. This discovery was a huge breakthrough in the field of DLC coatings, and the recent years have seen substantial progress in DLC films-related research and application [3,4-11]. Amorphous carbon consists of a mixture of $\mathrm{sp}^{3}, \mathrm{sp}^{2}$, and even $\mathrm{sp}^{1}$ bonded atoms, with hydrogen either present or absent [13] Diamond-like coatings can have a variety of structures. Their properties are dependent on the deposition methods and the parameters used, with another important factor being the graphite $\mathrm{sp}^{2}$ to diamond $\mathrm{sp}^{3}$ ratio. The coatings can be doped with metals (W, Ti, Nb, Cr, V, Co, Mo) and non-metals (H, Si, F, N, O, $\mathrm{P}, \mathrm{B})$, which improves their properties while maintaining their amorphous character [3,5,13-14].

Most DLC coatings are capable of providing high hardness (10-60 GPa), a low coefficient of friction (below 0.1), high resistance to abrasion (up to $10^{-7} \mathrm{~mm}^{3} / \mathrm{Nm}^{-1}$ ), chemical resistance, high electrical resistivity $\left(10^{16} \mathrm{Wcm}\right)$ and optical transparency in visible and IR spectra. The resistance of the coatings against cracking and subsequent delamination during screwing is critical [15]. In addition to material parameters, which define the properties of the films, the friction testing conditions contribute to their friction and wear values [3,6,10-11].

Owing to their unique properties, DLC coatings have a wide range of applications, for example, in electronics, for automobiles, in the textile industry, as medical devices and as wear resistant films for MEMS and NEMS devices [3,5-7,11].

Another group of materials as commonly used in lubricated friction pairs is ionic liquids. Ionic liquids, ILs, are the organic substances with the moderate melting point lower than the temperature of boiling water. Salts that melt at temperatures lower than room temperature $\left(25^{\circ} \mathrm{C}\right)$ comprise a special group called room-temperature ionic liquids, RTILs $[11,16]$. The term ionic liquids does not refer only to ionic compounds that melt at room temperature, but to all ionic compounds melting below $100^{\circ} \mathrm{C}$. Because of their extraordinary characteristics, they have been

* KIELCE UNIVERSITY OF TECHNOLOGY, $7^{\text {th }}$ TYSIACLECIA P.P. AV. 25-314 KIELCE, POLAND

** UNIVERSITY OF LIFE SCIENCE IN LUBLIN, POLAND

\# Corresponding author: mmadej@tu.kielce.pl 
widely and extensively studied since the beginning of the 1990 s [11,16-20]. Ionic liquids were first used as lubricant fluids in 2001. Good lubrication properties of ionic liquids are the result of their polar structure, the capability to produce adsorbed and organised boundary layers and tribochemical interaction with metallic surfaces $[11,18]$. Those liquids which maintain flowability below $-50^{\circ} \mathrm{C}$ exhibit high thermal stability, nonflammability and negligible volatility, along with an ability to provide lubrication for many hours of work $[16,18]$. Unique properties of ionic liquids render them excellent lubricants. These properties include appropriate viscosity, good wettability, good adhesion on metallic and ceramic surfaces, a wide liquid state temperature range, high heat resistance, the absence of volatility, nonflammability, good heat conductivity facilitating the removal of heat from the friction zone, and recoverability and recycling potential $[16,18,20]$.

Ionic liquids have been found to have lubricant tribological properties comparable to or better than commercial lubricants, including PFPE and X-1P, demonstrating at the same time high resistance to heat and load [18], being an attractive alternative to traditional mineral and synthetic lubricating fluids due to their lubrication properties in extreme conditions, anti-wear characteristics and high capability to carry loads. This results from the polar structure of ionic liquids and their ability to produce strong adsorbed, ordered layers on metallic surfaces.

\section{Experimental}

\subsection{Materials}

The elements of the tribological systems used in this study were diamond-like a-C:H coatings deposited on steel components by plasma assisted chemical vapour deposition at $<250^{\circ} \mathrm{C}$.

Conventional lubricants with a set of anti-wear additives usually contain toxic substances. Elimination of ecologically deleterious additives and replacing them with environmentally friendly substances is possible owing to the use of ionic liquids.

This paper evaluates the influence of ionic liquids on tribological characteristics of the systems with diamond-like coatings. 1-Butyl-3-methylimidazolium bis(trifluoromethylsulfonyl)imide (BMIM TFSI) was used as a lubricant. Table 1 shows the structure of the substance and Table 2 summarizes its physical properties

TABLE 1

The structure of 1-Butyl-3-methylimidazolium bis(trifluoromethylsulfonyl)imide

\begin{tabular}{|l|l|}
\hline \multicolumn{1}{|c|}{ Name } & \multicolumn{1}{c|}{$\begin{array}{c}\text { 1-Butyl-3-methylimidazolium } \\
\text { bis(trifluoromethylsulfonyl)imide }\end{array}$} \\
\hline Chemical formula & C10H15F6N3O4S2 \\
\hline Abbreviation & BMIM TFSI \\
Structure & \\
\hline Molar mass, $\mathrm{g} / \mathrm{mol}$ & 419.36 \\
\hline
\end{tabular}

TABLE 2

Properties of 1-Butyl-3-methylimidazolium bis(trifluoromethylsulfonyl)imide

\begin{tabular}{|l|c|}
\hline \multicolumn{1}{|c|}{ Liquid } & BMIM TFSI \\
\hline Appearance & Colourless liquid \\
\hline Density at $20^{\circ} \mathrm{C}, \mathrm{g} / \mathrm{cm}^{3}$ & 1.43 \\
\hline Viscosity at $25^{\circ} \mathrm{C}, \mathrm{mPa} \cdot \mathrm{s}$ & 61.14 \\
\hline Conductivity at $25^{\circ} \mathrm{C}, \mathrm{mS} / \mathrm{cm}$ & 3.9 \\
\hline Melting point, ${ }^{\circ} \mathrm{C}$ & -4 \\
\hline Flash point, ${ }^{\circ} \mathrm{C}$ & $>200$ \\
\hline Decomposition point, ${ }^{\circ} \mathrm{C}$ & 439 \\
\hline
\end{tabular}

\subsection{Microstructure and mechanical properties characterisation}

The structure was studied using a JSM 7100F microscope with an EDS detector manufactured by JEOL. The tests covered the observations of surface topography and cross-sections of the coatings, and a linear analysis (Linescan) and the surface distribution (Map/Mapping) allowed the identification of the elements present in the coatings.

The conventional methods of measuring surface microhardness are based on calculation of the ratio between the force applied to the indenter and the area of the impression after unloading. This route is impossible in the case of thin coatings. A much more accurate method consists of continuous measurement of the loading force and the displacement of the indenter into a sample during the loading-unloading cycle.

This test was carried out using an Anton Paar nanohardness tester NHT2 for determining micromechanical properties of materials. After one loading-unloading cycle, the load on the indenter was plotted as a function of its displacement being the indentation depth - as shown in Figure 1.

The analysis was performed based on:

- reduced modulus $\frac{1}{E^{*}}=\frac{1-v^{2}}{E}-\frac{1-v^{\prime 2}}{E^{\prime}}$

( $E-$ modulus of specimen, $E^{\prime}-$ modulus of intender)

- $\quad$ stiffness $S=\frac{d P}{d h}=2 E^{*} \frac{\sqrt{A}}{\sqrt{P}}$

- $\quad$ contact area $A=3 \sqrt{3} h_{p}^{2} \tan ^{2} 65.3=24.5 h_{p}^{2}$

where: $h p$ - penetration depth

- hardness $H=\frac{P}{24.5 h_{p}^{2}}$

- elastic modulus $E^{*}=\frac{d P}{d h} \frac{1}{2 h_{p}} \frac{1}{\beta} \sqrt{\frac{\pi}{24.5}}$

$\beta=1.034$ for Berkovich intender 
a)

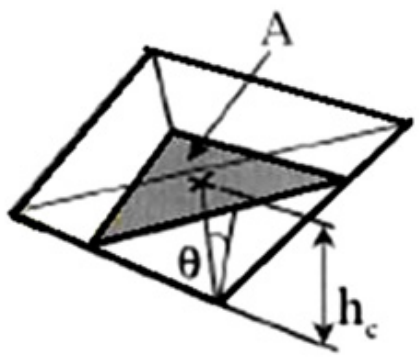

b)

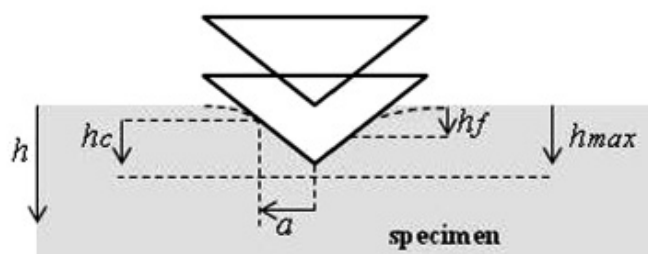

c)

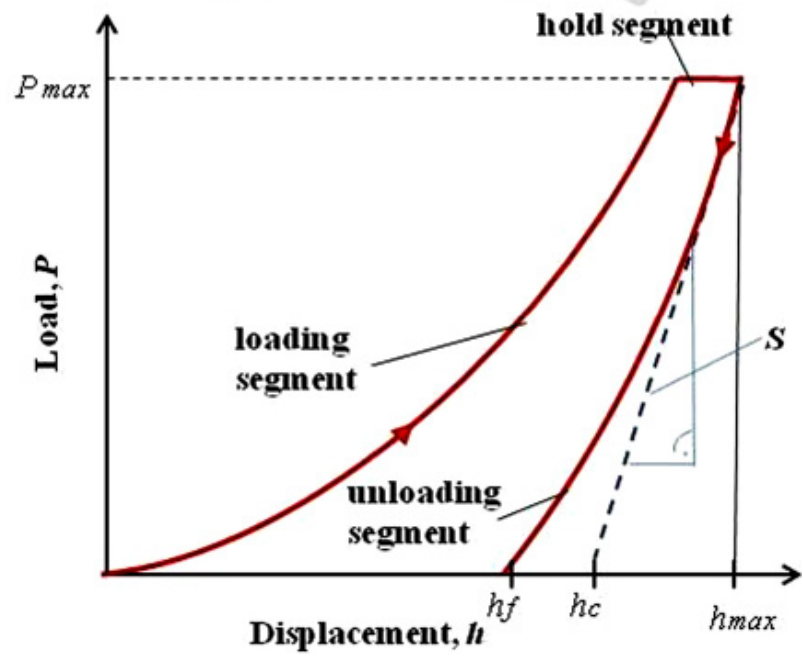

Fig. 1. Typical load-penetration depth curve $-P$-load, $h$-penetration depth and $h f$ - residual depth, $h c$ - contact depth, hmax - maximal depth, $S$ - contact stiffness

\subsection{Tribological tests}

The most commonly used device for evaluating tribological properties at a focused point contact is a T-01M ball-on-disc tester, which helps assess the resistance to wear and the coefficient of friction for pairs of materials operating in sliding motion. A pair tested is composed of a stationary ball pressed with force $P$ against the surface of a disc rotating at a predefined speed $n$. The following parameters were set for the test:

- friction pair: a ball made of $100 \mathrm{Cr} 6$ steel - a disc made of $100 \mathrm{Cr} 6$ steel or a ball made of $100 \mathrm{Cr} 6$ steel - a disc made of $100 \mathrm{Cr} 6$ steel coated with DLC film.

- $\quad$ load $P=10 \mathrm{~N}$

- $\quad$ sliding velocity $v=0.1 \mathrm{~m} / \mathrm{s}$.

- $\quad$ friction path $s=1000 \mathrm{~m}$.

- lubrication: no lubrication or ionic liquid-1-Butyl-3-methylimidazolium bis(trifluoromethylsulfonyl)imide,

- $\quad$ relative humidity $55 \pm 5 \%$.

- ambient temperature $T_{0}=22 \pm 1{ }^{\circ} \mathrm{C}$.

\section{Results}

\subsection{Microstructure and mechanical properties characterisation}

SEM analysis of the DLC coating structure covered the observations of the film surface topography and cross-sections. Figures 2-4 show the images of the DLC coating surface topography (Fig. 2a), cross-section and thickness (Fig. 2b), linear distribution of the elements (Fig. 3) and the map of the cross sectional distribution of individual elements (Fig. 4).

High-resolution observations of the DLC coating surface showed its amorphous character (Figure 3a). An intermediate layer of $454 \mathrm{~nm}$ in thickness was observed between the DLC film and the substrate. The basic DLC film had a thickness of about $1.6 \mu \mathrm{m}$. The film produced is homogeneous along its length. Linear analysis and the surface distribution showed that the intermediate layer is chiefly composed of chromium, with an increased content of tungsten accumulated at the bottom part of the DLC coating.

The hardness tests were conducted using a nanohardness tester NHT2 with the Berkovich indenter and the following pa-
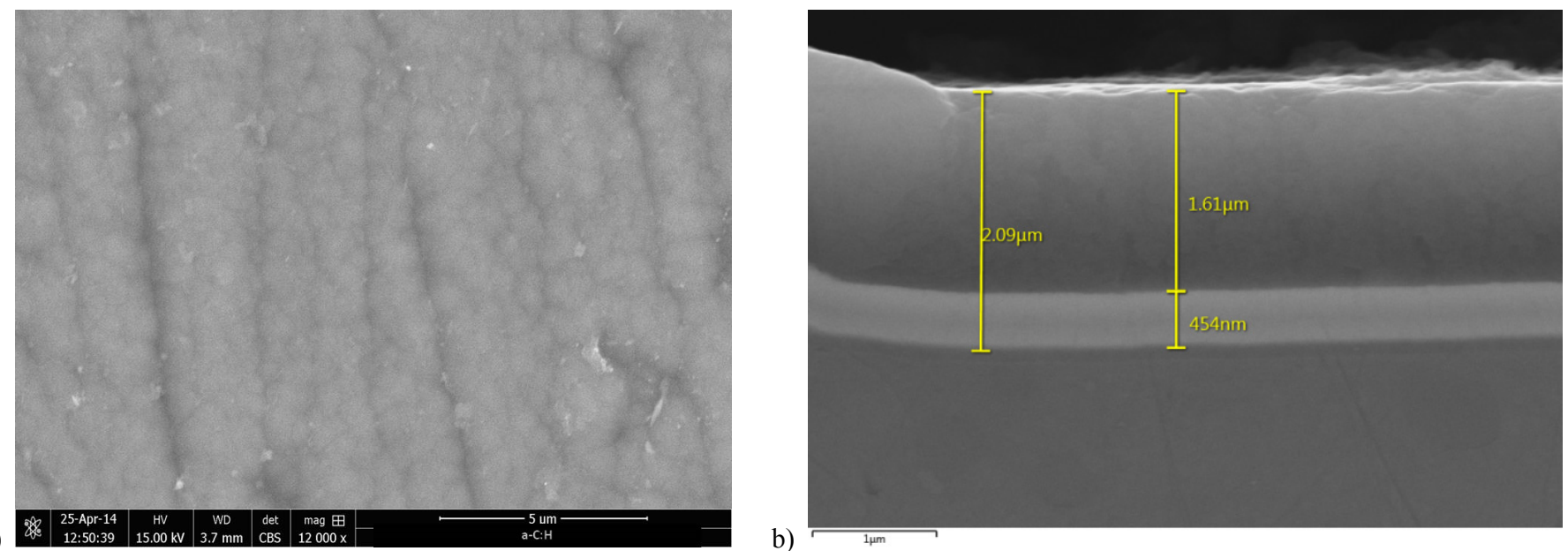

Fig. 2. SEM image of a) surface topography; b) cross sectional microstructure and the DLC coating thickness 


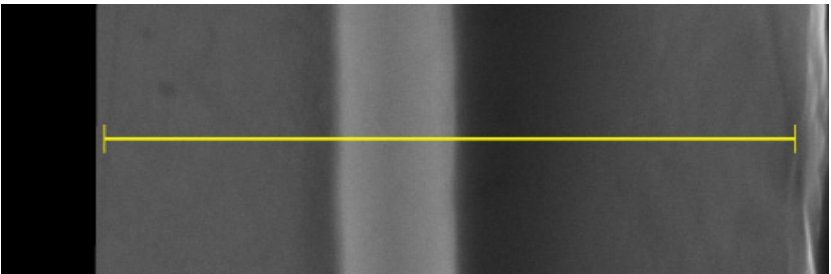

a)

b)

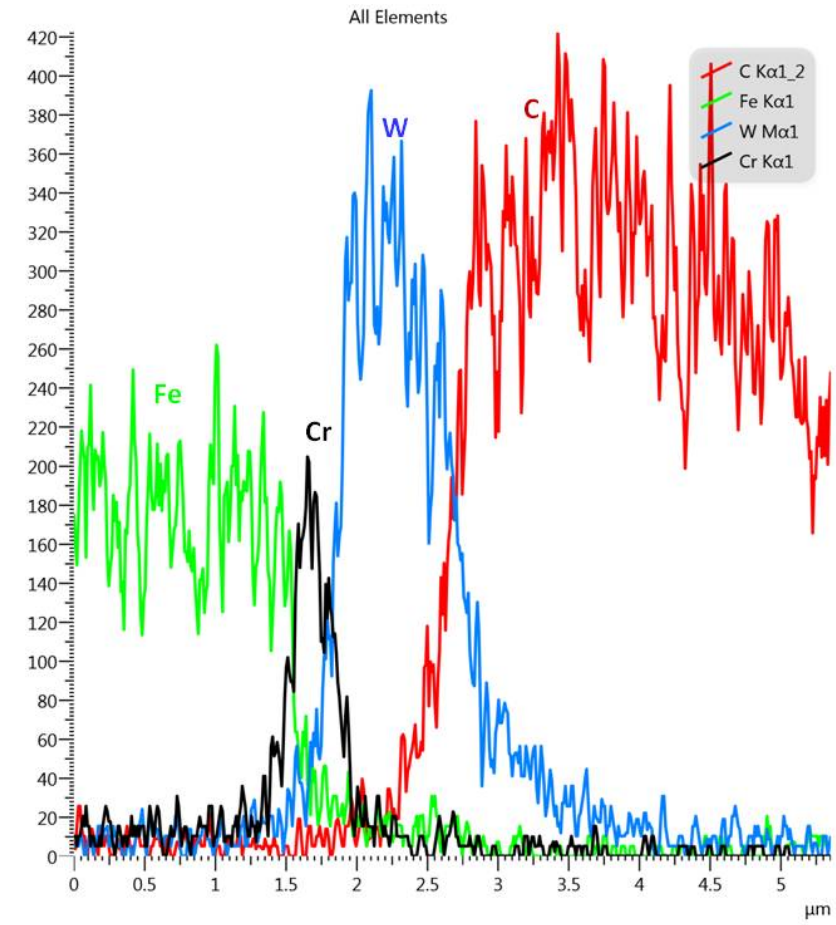

Fig. 3. SEM: a) cross sectional microstructure of the DLC coating; b) EDS analysis

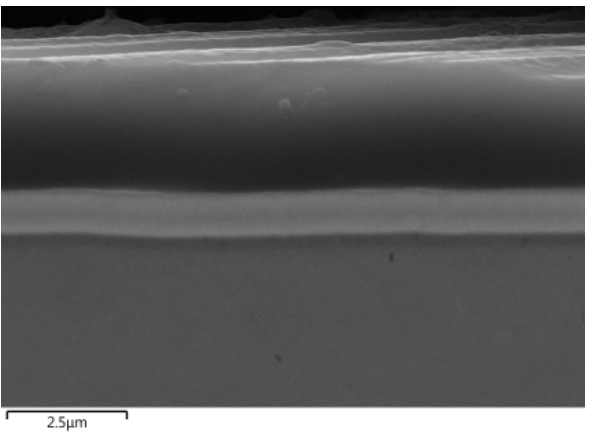

a)

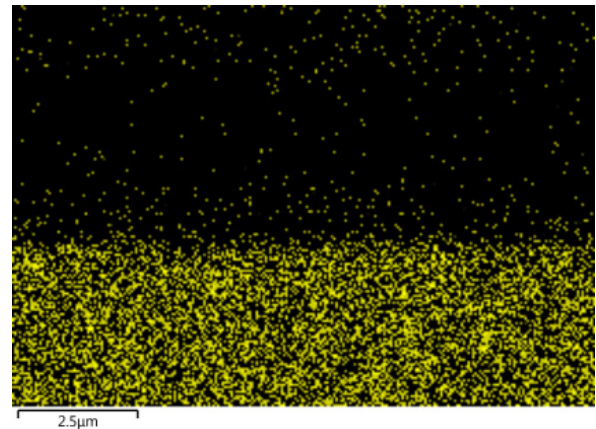

b)

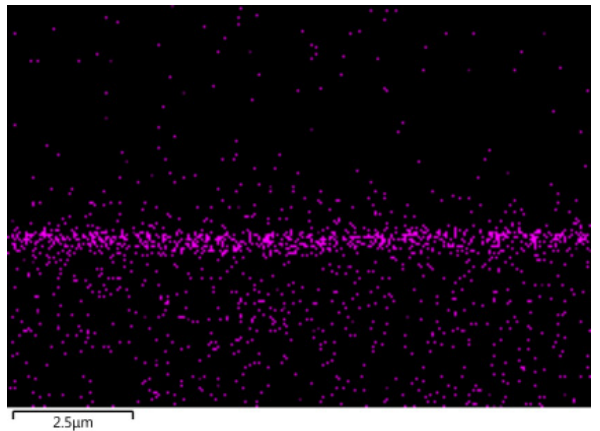

c)

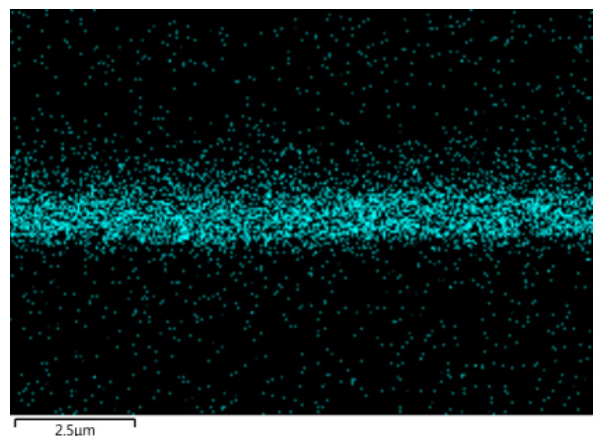

d)

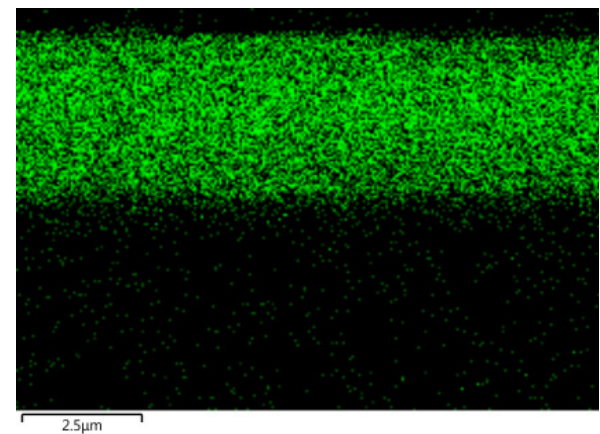

e)

Fig. 4. Element distribution maps in the cross-section of the DLC coating: a) view of the coating b) iron; c) chromium; d) tungsten; e) carbon

rameters taken for one cycle: $F=50 \mathrm{mN}, d F / d t=100 \mathrm{mN} / \mathrm{min}$, pause $=10.0 \mathrm{~s}$. The measurements were executed in the crosssection of the DLC coatings. The Young's modulus, stiffness, contact surface and hardness were calculated by the device based on the Oliver-Pharr model, taking the Poisson coefficient for the DLC coating to be $v=0.3$. Table 3 summarizes the measurement results.
TABLE 3

Results of hardness measurement

\begin{tabular}{|c|c|c|c|c|c|}
\hline \hline $\begin{array}{c}\text { Para- } \\
\text { meter }\end{array}$ & $\begin{array}{c}\text { Indentation } \\
\text { hardness, } \\
\mathbf{H}_{\text {IT }}\end{array}$ & $\begin{array}{c}\text { Vickers } \\
\text { hardness, } \\
\text { HV }\end{array}$ & $\begin{array}{c}\text { Elastic } \\
\text { modulus, } \\
\mathbf{E}^{*}\end{array}$ & $\begin{array}{c}\text { Stiffness, } \\
\mathbf{S}\end{array}$ & $\begin{array}{c}\text { Contact } \\
\text { area, A }\end{array}$ \\
\hline Value & $18 \mathrm{GPa}$ & $1678 \mathrm{HV}$ & $147 \mathrm{GPa}$ & $276 \mathrm{mN} / \mu \mathrm{m}$ & $2.76 \mu \mathrm{m}$ \\
\hline $\begin{array}{c}\text { Standard } \\
\text { deviation }\end{array}$ & 3 & 98 & 17 & 29 & 0.25 \\
\hline
\end{tabular}




\subsection{Wear}

Average values of the coefficient of friction and wear rate were determined on the basis of at least three full testing runs. Figure 5 summarizes average friction coefficients and wear rates from the test. Example plots of the coefficient of friction and the linear wear of the steel - steel and steel - DLC coating friction pairs lubricated with 1-Butyl-3-methylimidazolium bis(trifluoromethylsulfonyl)imide are presented in figure 6 .

The values of the coefficient of friction and wear rate presented in figures 5 and 6 were similar in the case of the pairs with diamond-like film-covered materials and substantially lower for the steel-steel pairs. The values of linear wear for the pairs with coatings were also lower than those for uncoated steel pairs.

The pair made up of the steel element with the diamondlike coating lubricated with the ionic liquid as a sliding element yielded the most favourable values of the friction coefficient and wear rate.

The coefficients of friction and linear wear values shown on the graphs clearly indicate that in addition to lower values of these parameters, their plots are more stable when DLC coatings are used.

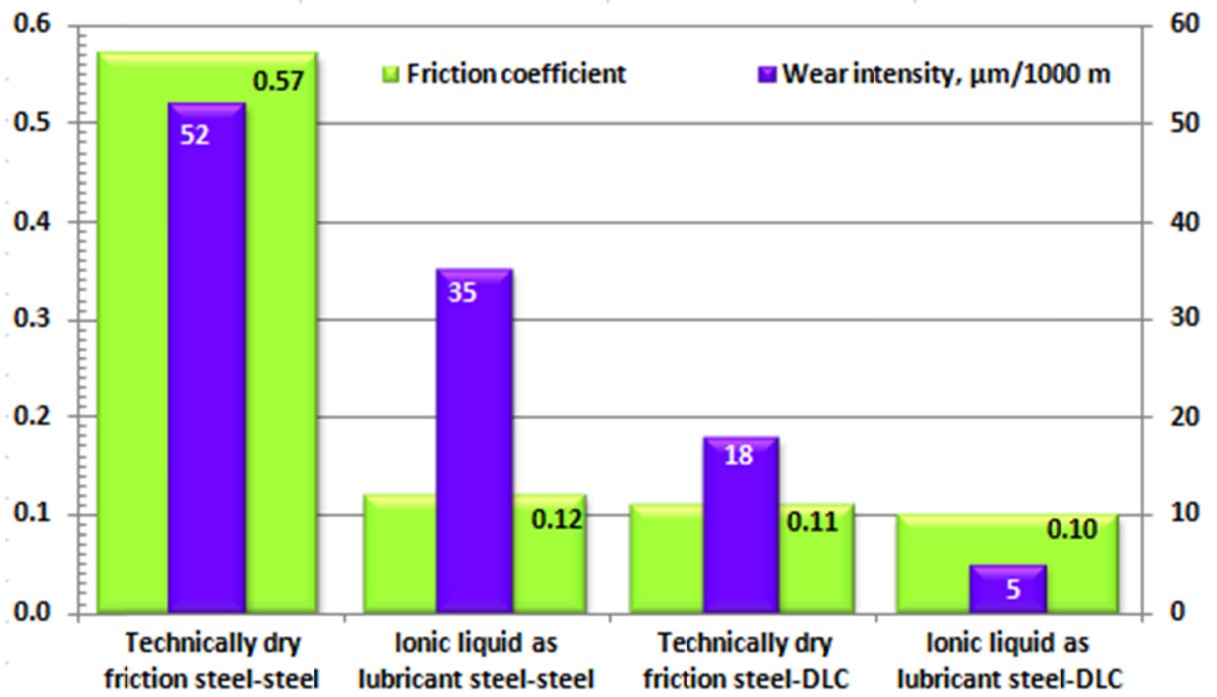

Fig. 5. Average values of the friction coefficient and wear rate for technically dry friction TTSand ionic liquid IL lubrication for steel-steel and steel DLC coating pairs

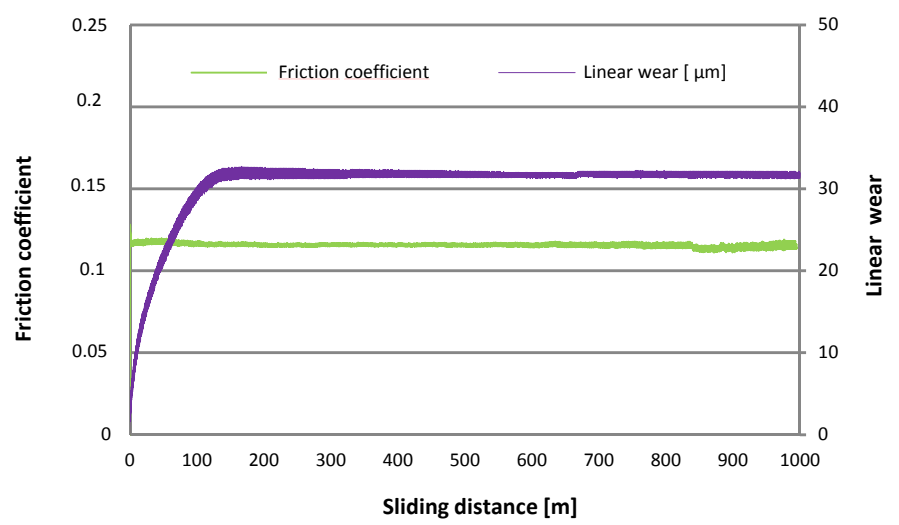

a)

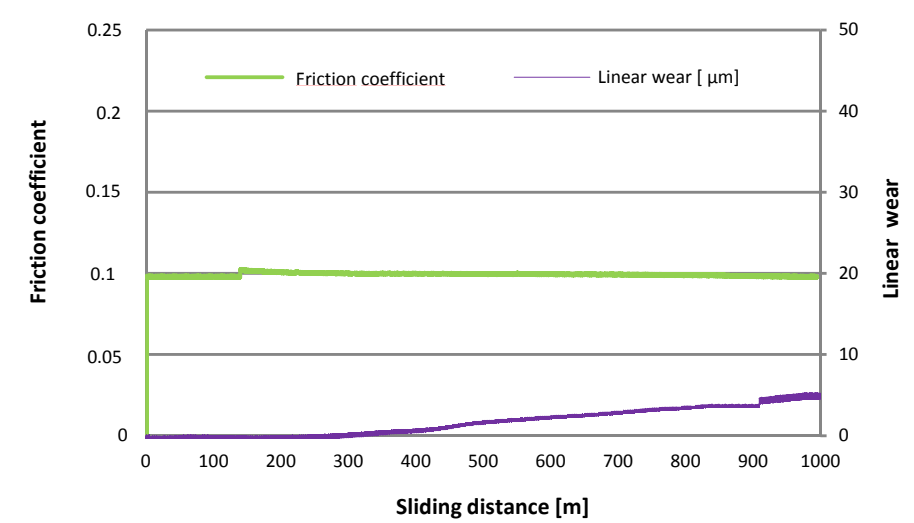

b)

Fig. 6. Plots of the coefficient of friction and the linear wear under ionic liquid lubrication: a) steel - steel and b) steel - DLC coating pairs

\section{Conclusions}

Observations of the structure indicated that the coating produced satisfied the quantitative requirements, that is, the film was compact across the entire surface and had no defects (discontinuities, cracks, pores).

The analyses confirmed the complex character of the DLC coating. The intermediate layer of chromium significantly im- proved the coating's adhesion. Tungsten present in the bottom part contributed to the expected improvement of performance characteristics - reduction in residual stress at the coatingsubstrate interface - confirmed by the absence of cracks in the coating. The coatings under investigation greatly increase hardness in relation to the substrate. Friction surfaces coated with the DLC films have better tribological properties compared with the uncoated surfaces both under dry friction and when lubricated 
with ionic liquids. This suggests that the diamond-like coating deposited on the elements exposed to tribological wear under dry friction is capable of adopting anti-wear function of the lubricant. Thus, it is possible to enhance the resistance to wear at simultaneous elimination of additives harmful to the environment.

The use of ionic liquid as a lubricant in the tribological systems under investigation confirmed its excellent lubrication properties resulting from the ability to produce strongly adsorbed, organised reactive-adsorptive layers and tribological interaction with the friction surface.

\section{REFERENCES}

[1] R. Burdzik, Ł. Konieczny, B. Łazarz, Acta Metallurgica Slovaca - Conference 4, 198 (2014)

[2] Stachowiak, W. Zwierzycki, Tribology International 44, 1216 (2011).

[3] M. Madej, Wear 317(1-2), 179 (2014).

[4] R. Michalczewski, W. Piekoszewski, M. Szczerek, W. Tuszyński, Tribology International 42, 554 (2009).

[5] M. Madej, D. Ozimina, K. Kurzydłowski, T. Płociński, P. Wieciński, M. Styp-Rekowski, M. Matuszewski, Transactions of FAMENA 39(1), 79 (2015)

[6] E. Zdravecká, V.Tiainen, Y. Konttinen, L. Franta, M. Vojs, M. Marton, M. Ondác, J. Tkácová, Vacuum 86, 675 (2012).
[7] M. Madej, D. Ozimina, I. Piwoński, A. Kisielewska, Metallic Materials 4, 297 (2012).

[8] M. Abdollah, Y. Yamaguchi, T. Akao, N. Inayoshi, N. Miyamoto, T. Tokoroyama, N. Umehara, Wear 274-275, 435 (2012).

[9] R. Michalczewski, W. Piekoszewski, Finish J. of Tribology 26, 9 (2007).

[10] K. Holmberg, H. Ronkainen, M. Matthews, Ceramics International 26, 787 (2000).

[11] M. Madej, K. Marczewska-Boczkowska, D. Ozimina, Przemysł Chemiczny 93(4), 500 (2014).

[12] S. Aisenberg, R. Chabot, Journal of Applied Physics 42, 2953 (1971).

[13] C. Donnet, A. Erdemir (Eds.), Tribology of diamond-like carbon films. Fundametals and applications, New York 2008.

[14] F. Zhiqiang, S. Jian, W. Chengbiao, Z. Wei, Y. Wen, P. Zhijian, Y. Xiang, L. Songsheng, D. Mingjiang, Vacuum 94, 14 (2013).

[15] M. Kot, B. Major, J.M. Lackner, Materials and Design 51, 280 (2013).

[16] P. Wasserscheid, T. Welton, Ionic Liquids in Synthesis, Weinheim 2008.

[17] I. Minami, Molecules 14, 2286 (2009).

[18] M. Kosmulski, J. Rosenholm, C. Saneluta, K. Marczewska-Boczkowska, J. Colloid Interface Sci. 291(1), 214 (2005).

[19] F. Zhou, Y. Liang, W. Liu, Chem. Soc. Rev. 38, 2590 (2009).

[20] T. Predel, B. Pohrer, E. Schluckre, Chem. Eng. Tech. 33, 132 (2010). 